\title{
MODERN DRESSING WOUND CARE MEMPERCEPAT PROSES PENYEMBUHAN ULKUS KAKI PADA PASIEN DIABETES: A SISTEMATIK REVIEW
}

\section{Modern Wound Care Dress for Acceleration of Foot Ulcus Healing Process in Diabetes Patients: a Systematic Review}

\author{
Bangu 1* \\ Heriviyatno Julika \\ Siagian ${ }^{2}$ \\ Rosani Naim ${ }^{3}$ \\ Evodius Nasus ${ }^{4}$ \\ 1,2,3,4 Program Studi DIII \\ Keperawatan Tiga/Fakultas \\ Sains \& Teknologi, Universitas \\ Sembilanbelas November, \\ Kolaka, Indonesia \\ *email: \\ abangakper65@gmail.com
}

\begin{abstract}
Abstrak
Ulkus kaki pada pasien diabetes harus mendapatkan perawatan untuk mengurangi resiko infeksi dan amputasi, serta memperbaiki fungsi dan kualitas hidup. Teknik perawatan luka berkembang sangat cepat yang bisa membantu perawat dan pasien untuk mempercepat proses penyembuhkan ulkus kaki pada pasien diabetes. Beberapa metode perawatan luka yang dapat mempercepat proses penyembuhan ulkus kaki pada Pasien DM. Anatara lain : Perawatan luka modern (modern wound dressing), proses penyembuhan luka ulkus diabetikum

dengan metode modern dressing, perawatan luka kronis dengan modern dressing, potensi teh hijau dalam penyembuhan luka, Madu sebagai agen debridement: sistematik revie. Tujuan : penelitian ini untuk meninjau beberapa metode dressing yang mempercepat proses penyembuhan ulkus kaki pada pasien diabetes. Metode: Penelitian ini menggunakan Systematic Review berdasarkan Preferred Reporting Items for Systematic Reviews \& Meta-Analyses (PRISMA) untuk mengidentifikasi semua literature yang di publikasikan menggunakan database dan kata kunci yang relevan. Hasil : Pada 5 artikel yang telah kami lakukan analisis, khusus penggunaan modern wound dressing terbukti lebih ampuh percepatan proses penembuhan luka khususnya ulkus kaki pada pasien diabetes. Kesimpulan : Perawatan luka modern (Modern wound dressing), perawatan luka kronis dengan modern dressing, potensi teh hijau dalam penyembuhan luka, Madu sebagai agen debridement: sistematik revie.dan peran keluarga membantu pasein minum obat secara teratur adalah pilihan yang tepat untuk mempercepat proses penyembuhan ulkus kaki pada pasien diabetes dengan efektifitas biaya perawatan yang lebih hemat.
\end{abstract}

\section{Kata Kunci:}

Diabetes Mellitus

Modem Wound dressing

Ulkus Kaki

Penyembuhan

\section{Keywords:}

Diabetes Mellitus

Modern Wound Dressing

Foot Ulcer

Healing

\begin{abstract}
Foot ulcers in diabetic patients should receive treatment to reduce the risk of infection and amputation, as well as improve function and quality of life. Wound care techniques are developing very quickly which can help nurses and patients to improve the healing of foot ulcers in diabetic patients. Several wound care methods that can accelerate the healing process of foot ulcers in DM patients include modern wound dressings, the process of healing diabetic ulcers. with modern dressing methods, chronic wound care with modern dressings, the potential of green tea in wound healing, honey as a debridement agent. Objective: This study is to review several dressing methods that accelerate the healing process of foot ulcers in diabetic patients. Methods: This study uses a Systematic Review based on Preferred Reporting Items for Systematic Reviews \& Meta-Analyses (PRISMA) to identify all published literature using relevant databases and keywords. Results: In the 5 articles that we analyzed, specifically the use of modern wound dressings proved to be more effective in accelerating the wound healing process, especially foot ulcers in diabetic patients. Conclusion : Modern wound care (Modern wound dressing), chronic wound care with modern dressings, the potential of green tea in wound healing, Honey as a debridement agent: a systematic review. And the role of the family in helping patients take medication regularly is the right choice to accelerate the healing process foot ulcers in diabetic patients with more cost-effective treatment.
\end{abstract}




\section{PENDAHULUAN}

Diabetes melitus adalah suatu kumpulan gejala yang timbul pada seseorang yang disebabkan oleh karena adanya peningkatan kadar glukosa darah akibat penurunan sekresi insulin yang progresif [I]. Diabetes melitus berhubungan dengan risiko aterosklerosis dan merupakan predisposisi untuk terjadinya kelainan mikrovaskular seperti retinopati, nefropati dan neuropati [2].

Peningkatan jumlah penderita DM yang terjadi secara konsisten menunjukkan bahwa penyakit DM merupakan masalah kesehatan yang perlu mendapat perhatian khusus dalam pelayanan kesehatan. Indonesia menempati peringkat ke-7 di dunia sebesar 10,0 juta jiwa, dimana peringkat pertama diduduki oleh China dengan jumlah penderita DM 109,6 juta jiwa [3]. Menurut Laporan Riset Kesehatan Dasar Kementerian Kesehatan Indonesia tahun 2018 yaitu terdapat I.5\% atau diperkirakan sekitar I.017.290 penduduk Indonesia menderita penyakit diabetes mellitus [4].

Meningkatnya jumlah penderita diabetes mellitus menyebabkan peningkatan kejadian komplikasi diabetes. Pada penderita DM banyak yang mengeluhkan terjadinya ulkus kaki diabetik sehingga menjadi penyebab terjadinya amputasi kaki pada penderita DM. Amputasi terjadi 15 kali lebih sering pada penderita diabetes dari pada non diabetes [5].

Prevalensi penderita ulkus kaki diabetik sekitar I5\% dengan risiko amputasi $30 \%$, angka mortalitas 32\%, dan di Indonesia ulkus kaki diabetik merupakan penyebab paling besar untuk dilakukan perawatan di rumah sakit sebesar $80 \%$. Selain itu angka kematian I tahun paska amputasi sebesar 14,8\%. Kewaspadaan terhadap persoalan kesehatan kaki diabetes di Indonesia juga masih sangat kurang. Sarana pelayanan kaki diabetik yang masih terbatas dan kurangnya tenaga kesehatan terlatih tentang pelayanan kaki diabetik menyebabkan pelayanan kaki pada pasien diabetes di Indonesia masih kurang diperhatikan [5]
Luka kaki diabetes disebabkan oleh beberapa faktor, yaitu neuropati, trauma, deformitas kaki, tekanan tinggi pada telapak kaki dan penyakit vaskuler perifer. Pemeriksaan dan klasifikasi ulkus diabetes yang menyeluruh dan sistematik dapat membantu memberikan dan arahan perawatan yang adekuat. Dasar dari perawatan ulkus diabetes meliputi 3 hal yaitu debridement, offloading, dan kontrol infeksi. Ulkus kaki pada pasien diabetes harus mendapatkan perawatan karena ada beberapa alasan, misalnya untuk mengurangi resiko infeksi dan amputasi, memperbaiki fungsi dan kualitas hidup, dan mengurangi biaya pemeliharaan kesehatan [6].

Perawat mempunyai peran yang sangat menentukan dalam merawat pasien diabetes mellitus dengan cara membuat perencanaan untuk mencegah timbulnya luka kaki diabetes dengan cara melakukan perawatan kaki, mengendalikan beban pada kaki, memotong kuku, inspeksi kaki setiap hari, menjaga kelembaban, menggunakan alas kaki yang sesuai dan melakukan olah raga kaki [7]. Rumah Sakit di Indonesia masih menggunakan balutan konvensional, yaitu menggunakan kasa steril sebagai bahan utama balutan.

Pentingnya peran keluarga dalam merawat anggota keluarganya dan membantu minum obat secara teratur. Keluarga harus bersabar agar mereka tidak stress guna untuk meningkatkan status kesehatan penderita. Karena status kesehatan penderita sangat ditentukan oleh seberapa aktif peran keluarga dalam memberikan perawatan bagi anggota keluarganya [8]. Hasil riset mengatakan tingkat kejadian infeksi pada perawatan luka dengan cara konvensional lebih tinggi dibandingkan dengan mengguanakan balutan modern dapat memberikan hasil yang signifikan dalam perbaikan luka diabetes (Sharp A \& Mc Comick, 2002). Penanganan luka diabetik secara efektif dapat mencegah terjadinya amputasi pada kaki itu sendiri, sehingga beban fisik dan psikologis pada pasien kaki diabetik dapat dikurangi . 


\section{METODOLOGI}

Sumber Data Metode yang digunakan dalam penulisan ini adalah Systematic Review berbasis jurnal, dengan beberapa tahap yakni ; penentuan topik besar, screenning journal, coding journal, dan menentukan tema dari referensi jurnal yang didapatkan. Penulusuran internet database yang digunakan diantaranya Google Scholar sebanyak 133 artikel dan PubMed sebaanyak 22 artikel yang dianalkisis. Peneliti hanya menemukan 5 artikel yang memenuhi kriteria penelitian.

\section{Strategi Pencarian}

Studi literatur dilakukan dengan cara menelaah artikel penelitian yang terpublikasi terkait dengan pertanyaan klinis yang sudah dibuat. Kata kunci yang digunakan dalam pencarian literatur ini adalah "Modern Wound Dressing” AND “Prosese penyembuhan” AND “Ulkus kaki” OR "Diabetes Mellitus“. Berdasarkan hasil pencarian, didapatkan 5 artikel RCT (randomized controlled trial) secara spesifik memenuhi syarat kriteria inklusi dan kriteria ekslusi.

Periode publikasi tahun 2010 sampai 2020. Untuk merancang kriteria artikel kami menggunakan format PICO sebagai berikut : Komponen PICO P : Pasien Diabetes dengan luka Ulkus di kaki / Diabetic Foot Ulcer I : Perawatan luka / Modern Wound Dressing C : Perawatan luka konvensional / Conventional Therapy / Kelompok Kontrol O : Perawatan luka terbaik untuk mempercepat proses penyembuhan luka diabetic

\section{Kriteria Inklusi dan Ekslusi}

Kriteria inklusi dari penelitian ini adalah: (I) Artikel memiliki peer review; (2) Memiliki intervensi yang cukup jelas; (3) Isi artikel relevan dengan topik bahasan; (4) Artikel dapat di download dalam bentuk full text; (5) Artikel Randomized Controlled Trial.

Kriteria Ekslusi yang sudah ditentukan dalam penelitian ini yaitu: (I) Artikel tidak memenuhi komponen suatu artikel yang baik (terdiri dari Abstract, Introduction, Methods, Results, Discussions, Implications, dan References); (2) Artikel bersifat review. Rincian strategi pencarian artikel yang memenuhi syarat ditinjau dan dianalisis dalam Prisma Diagram sebagai berikut :

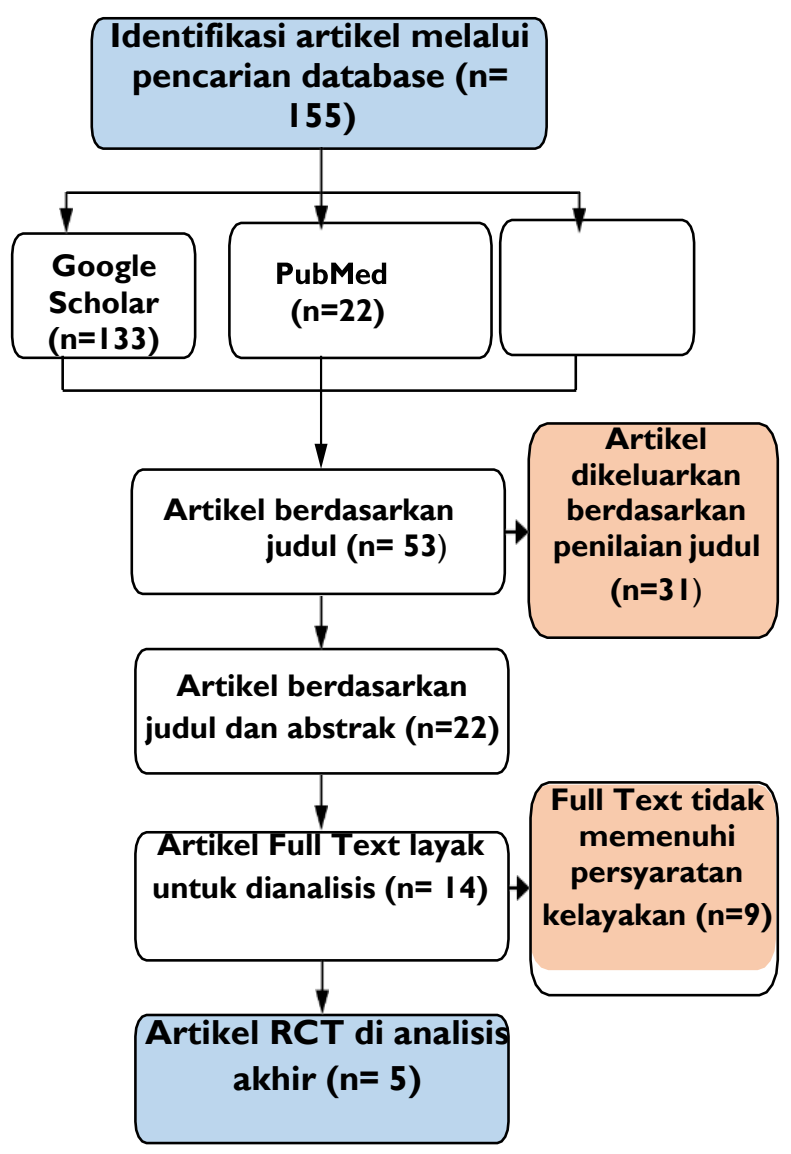

Gambar I. Ringkasan Proses Hasil Pencarian Artikel

Analisis

Efektivitas Proses Penyembuhan Luka dengan Penggunaan Modern Wound Dressing pada Pasien Ulkus Diabetik dijelaskan dengan menganalisis artikel dari hasil pencarian sebanyak 5 artikel yang memenuhi syarat untuk dianalisis.

Dari 7 artikel yang telah kami lakukan analisis, penggunaan Metode Modern Wound Dressing telah di gunakan di beberapa Negara seperti Prancis, Iran, Korea, London, South Florida, dan Amerika Serikat. Populasi dan Sampel dalam studi penelitian ini adalah pasien dengan luka ulkus kaki diabetik dan didominasi oleh laki-laki dengan rentang usia 12-75 tahun. 
Penelitian ini dilakukan secara deskriptif tentang perawatan luka kaki diabetes dengan menggunakan Modern Wound Dressing. Dalam studi penelitian ini terdapat 5 artikel menggunakan desain Randomized Controlled Trial (RCT) yang di terbitkan sampai dengan kepercayaan $95 \%$ juga disajikan dalam proses analisis.

\section{HASIL DAN PEMBAHASAN}

\section{HASIL}

Berdasarkan hasil pencarian dengan menggunakan 2 electronic database yaitu Google Scholar dan PubMed, pada diagram alur prisma didapatkan 155 artikel, kemudian dilakukan proses seleksi jurnal berdasarkan judul terdapat 53 artikel yang relevan. Setelah dilakukan penilaian yang sesuai dengan judul dan abstrak maka dikeluarkan 3I artikel. Dari 22 artikel yang relevan setelah dilakukan seleksi kembali secara keseluruhan (full text) didapatkan 14 artikel full teks memenuhi standar kelayakan (eligibility) setelah penulis menyeleksi kembali terdapat 9 artikel full teks yang tidak memenuhi persyaratan kelayakan dan dikeluarkan hasil akhir tinggal 5 artikel yang membahas tentang penggunaan Modern Wound Dressing dalam perawatan Ulkus Kaki Diabetik sebagai upaya meningkatkan proses penyembuhan luka.
Hasil analisis yang dilakukan terhadap 5 artikel, metode intervensi yang terbukti signifikan dapat meningkatkan proses penyembuhan luka kaki diabetik dan efektifitas biaya perawatan lebih hemat dengan menggunakan: (I) Perawatan luka modern (modern wound dressing, (2) Proses penyembuhan luka ulkus diabetikum dengan metode modern dressing, (3) Perawatan luka kronis dengan modern dressing, (4) potensi teh hijau dalam penyembuhan luka dan (5) Madu sebagai agen debridement: sistematik reviwe. 
Tabel 2. Daftar Artikel Yang Sesuai Dengan Penelitian $(n=5)$

\begin{tabular}{|c|c|c|c|c|c|}
\hline $\begin{array}{c}\text { Penulis } \\
\text { Pertamal ludul }\end{array}$ & Tahun & Nama Jurnal & Tujuan & Metode & Hasil \\
\hline 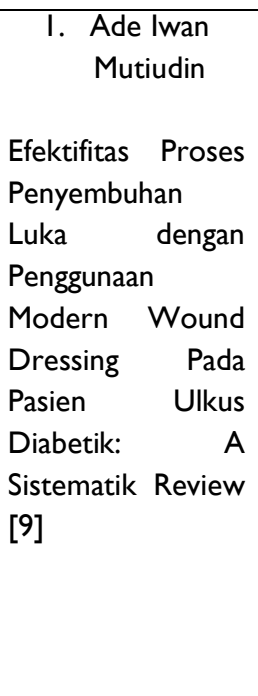 & 2019 & $\begin{array}{l}\text { Jurnal Keperawatan \& } \\
\text { Kebidanan }\end{array}$ & $\begin{array}{l}\text { Untuk meninjau } \\
\text { dan mengetahui } \\
\text { mengenai } \\
\text { efektivitas proses } \\
\text { penyembuhan } \\
\text { luka dengan } \\
\text { intervensi } \\
\text { penggunaan } \\
\text { metode Modern } \\
\text { Wound Dressing } \\
\text { pada pasien } \\
\text { Ulkus kaki } \\
\text { diabetik }\end{array}$ & $\begin{array}{l}\text { Systematic } \\
\text { Review } \\
\text { berdasarkan } \\
\text { Preferred } \\
\text { Reporting for } \\
\text { Items } \\
\text { Systematic } \\
\text { Reviews \& } \\
\text { Meta-Analyses } \\
\text { (PRISMA) } \\
\text { untuk } \\
\text { mengidentifikasi } \\
\text { semua } \\
\text { literature yang } \\
\text { di publikasikan } \\
\text { menggunakan } \\
\text { database dan } \\
\text { kata kunci yang } \\
\text { relevan. }\end{array}$ & $\begin{array}{l}\text { Modern Wound } \\
\text { Dressing dalam } \\
\text { perawatan Ulkus Kaki } \\
\text { Diabetik sebagai upaya } \\
\text { meningkatkan proses } \\
\text { penyembuhan luka. } \\
\text { Hasil analisis artikel } \\
\text { yang sudah dilakukan } \\
\text { metode intervensi } \\
\text { modern dressing } \\
\text { terbukti signifikan dapat } \\
\text { meningkatkan proses } \\
\text { penyembuhan luka kaki } \\
\text { diabetik dan efektifitas } \\
\text { biaya perawatan lebih } \\
\text { hemat }\end{array}$ \\
\hline $\begin{array}{l}\text { 2. Saryono } \\
\text { Potensi Teh } \\
\text { Hijau Dalam } \\
\text { Penyembuhan } \\
\text { Luka:Sistematik } \\
\text { Review [10] }\end{array}$ & 2013 & $\begin{array}{l}\text { Prosiding Konferensi } \\
\text { Nasional PPNI Jawa } \\
\text { Tengah }\end{array}$ & $\begin{array}{l}\text { Untuk } \\
\text { menguraikan } \\
\text { peran teh hijau } \\
\text { dalam } \\
\text { penyembuhan } \\
\text { luka dan potensi } \\
\text { penggunaannya } \\
\text { pada perawatan } \\
\text { ulkus dibetik } \\
\text { pada manusia. }\end{array}$ & $\begin{array}{l}\text { Sistematik } \\
\text { review. Artikel } \\
\text { didapat dari } \\
\text { database } \\
\text { elektronik } \\
\text { seperti } \\
\text { PubMed, } \\
\text { ScienceDirect, } \\
\text { dan Google } \\
\text { Scholar yang } \\
\text { dipublikasi dari } \\
\text { tahun 2007 } \\
\text { hingga 2013. }\end{array}$ & 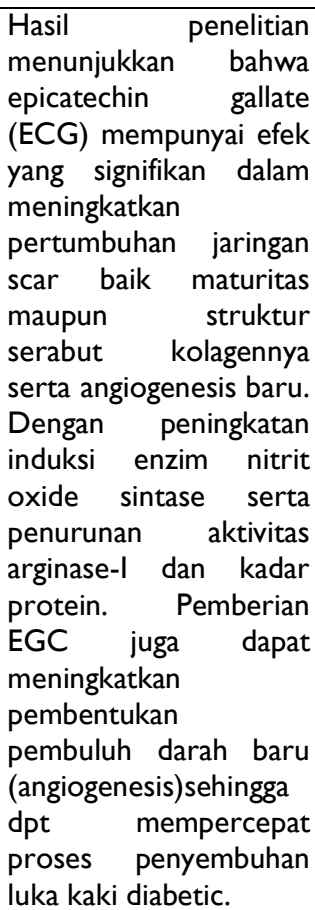 \\
\hline $\begin{array}{l}\text { Perawatan } \\
\text { Luka Kronis } \\
\text { dengan } \\
\text { Modern } \\
\text { Dressing; } \\
\text { Sistematik } \\
\text { Review [Il] }\end{array}$ & 2015 & $\begin{array}{l}\text { Cermin Dunia } \\
\text { Kedokteran }\end{array}$ & $\begin{array}{l}\text { Memahami } \\
\text { konsep } \\
\text { penyembuhan } \\
\text { luka lembap, } \\
\text { pemilihan bahan } \\
\text { balutan, dan } \\
\text { prinsip-prinsip } \\
\text { intervensi luka } \\
\text { yang optimal } \\
\text { merupakan } \\
\text { konsep kunci } \\
\text { untuk } \\
\text { mendukung } \\
\text { proses } \\
\text { penyembuhan } \\
\text { luka }\end{array}$ & $\begin{array}{l}\text { Sistematik } \\
\text { review }\end{array}$ & $\begin{array}{l}\text { Jenis modern dressing } \\
\text { lain, yakni Ca Alginat, } \\
\text { kandungan Ca-nya } \\
\text { dapat membantu } \\
\text { menghentikan } \\
\text { perdarahan. Kemudian } \\
\text { ada hidroselulosa yang } \\
\text { mampu menyerap } \\
\text { cairan dua kali lebih } \\
\text { banyak dibandingkan } \\
\text { Ca Alginat. Selanjutnya } \\
\text { adalah hidrokoloid yang } \\
\text { mampu melindungi dari } \\
\text { kontaminasi air dan }\end{array}$ \\
\hline
\end{tabular}




\begin{tabular}{|c|c|c|c|c|c|}
\hline & & & & & 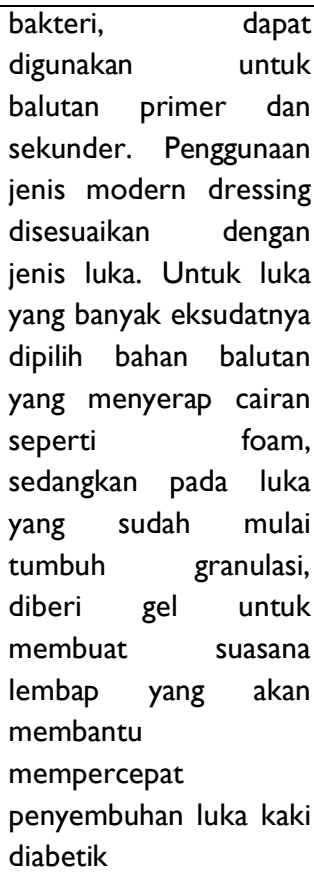 \\
\hline $\begin{array}{l}\text { 4. Sukri } \\
\text { Herianto } \\
\text { Ritonga } \\
\text { Madu sebagai } \\
\text { agen } \\
\text { Debridement: } \\
\text { sistematik } \\
\text { review [12] }\end{array}$ & 2016 & $\begin{array}{l}\text { Jurnal Kesehatan Ilmiah } \\
\text { Indonesia }\end{array}$ & $\begin{array}{l}\text { Untuk } \\
\text { mengidentifikasi } \\
\text { penelitian } \\
\text { mengenai peran } \\
\text { madu sebagai } \\
\text { agen } \\
\text { debridement } \\
\text { pada luka kaki } \\
\text { diabetik }\end{array}$ & $\begin{array}{l}\text { Metode } \\
\text { pencarian pada } \\
3 \text { database } \\
\text { elektronik yaitu } \\
\text { Medline, } \\
\text { Proquest dan } \\
\text { CINAHL. } \\
\text { Kriteria inklusi } \\
\text { berupa jurnal } \\
\text { merupakan } \\
\text { penelitian } \\
\text { kuantitatif, } \\
\text { tahun publikasi } \\
\text { diatas tahun } \\
2003 \text { dan jurnal } \\
\text { berkaitan } \\
\text { dengan madu } \\
\text { sebagai agen } \\
\text { debridement }\end{array}$ & $\begin{array}{l}\text { Madu dapat memicu } \\
\text { terjadinya autolisis baik } \\
\text { secara parsial ataupun } \\
\text { total. Waktu minimal } \\
\text { yang dibutuhkan untuk } \\
\text { terjadinya autolisis ini } \\
\text { adalah } 6 \text { hingga } 7 \text { hari. } \\
\text { Adapun rata-rata } \\
\text { terjadinya autolisis total } \\
\text { adalah 31, } 7 \text { hari. Pada } \\
\text { jaringan nekrotik } \\
\text { tingkat terlepasnya } \\
\text { jaringan nekrotik } 87 \% \\
\text { sedangkan } \\
\text { jaringan slough tingkat } \\
\text { terlepasnya mencapai } \\
90 \%\end{array}$ \\
\hline $\begin{array}{l}\text { 5. Rika } \\
\text { Fatmadonaa, } \\
\text { Elvi } \\
\text { Oktarinaa } \\
\text { Aplikasi } \\
\text { Modern } \\
\text { Wound Care } \\
\text { Pada } \\
\text { Perawatan } \\
\text { Luka Infeksi di } \\
\text { RS Pemerintah } \\
\text { Kota Padang.; } \\
\text { sistematik } \\
\text { review .[13] }\end{array}$ & 2016 & $\begin{array}{l}\text { NERS JURNAL } \\
\text { KEPERAWATAN,Volume } \\
\text { I2, No.2, }\end{array}$ & $\begin{array}{l}\text { Adalah untuk: } \\
\text { I. Mengurangi } \\
\text { dehidrasi } \\
\text { dan } \\
\text { kematian } \\
\text { sel. } \\
\text { fibroblast } \\
\text { dan perisit. } \\
\text { terjadi } \\
\text { pada } \\
\text { tekanan } \\
\text { oksigen } \\
\text { rendah, } \\
\text { balutan } \\
\text { "occlusive" } \\
\text { dapat } \\
\text { merangsan } \\
\text { g proses } \\
\text { angiogenesi } \\
\text { s ini. } \\
\text { Berperan } \\
\text { dalam }\end{array}$ & $\begin{array}{l}\text { Sistematik } \\
\text { review }\end{array}$ & $\begin{array}{l}\text { I. Holistic: praktek } \\
\text { yang baik } \\
\text { membutuhkan } \\
\text { pengkajian pasien } \\
\text { "whole"/secara } \\
\text { menyeluruh, bukan } \\
\text { "lubang pada } \\
\text { pasien"/"hole in the } \\
\text { patient". Semua } \\
\text { kemungkinan } \\
\text { faktor-faktor yang } \\
\text { berkontribusi harus } \\
\text { dieksplorasi } \\
\text { 2. Interdisciplinary: } \\
\text { perawatan luka } \\
\text { adalah bisnis yang } \\
\text { komplek dari } \\
\text { membutuhkan } \\
\text { ketrampilan }\end{array}$ \\
\hline
\end{tabular}




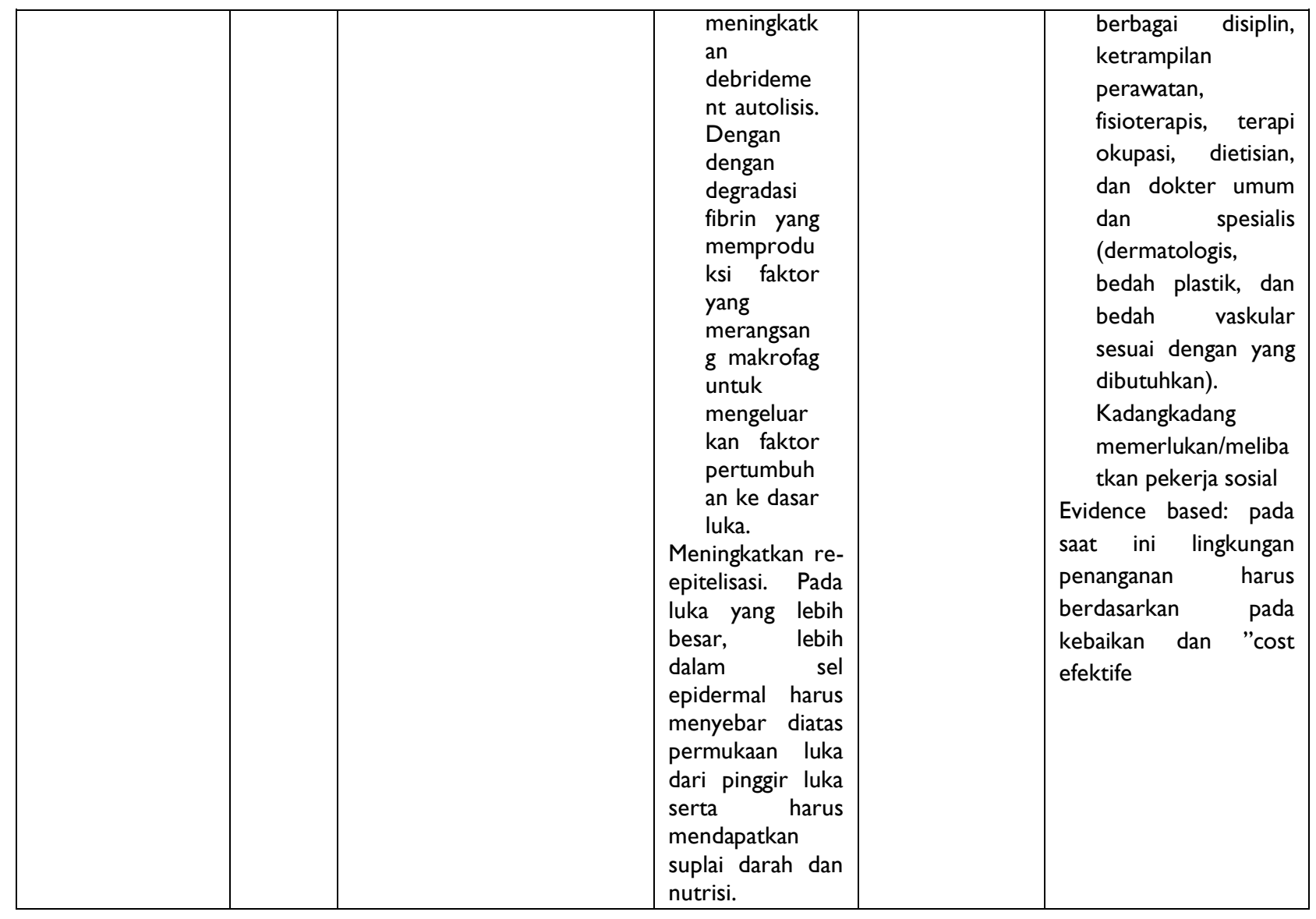




\section{PEMBAHASAN}

Artikel pertama: Penggantian balutan dilakukan sesuai kebutuhan tidak hanya berdasarkan kebiasaan, melainkan disesuaikan terlebih dahulu dengan tipe dan jenis luka. Penggunaan antiseptik hanya untuk yang memerlukan saja karena efek toksinnya terhadap sel sehat. Untuk membersihkan luka hanya memakai normal. Citotoxic agent seperti povidine iodine, asam asetat, seharusnya tidak secara sering digunakan untuk membersihkan luka karena dapat menghambat penyembuhan dan mencegah repitelisasi.

Intervensi perawatan luka dengan menggunakan Askina Calgitrol Ag tujuannya adalah menggabungkan efektifitas dari ion silver dengan kemampuan daya serap dari calcium alginate dan polyurethane foam yang memiliki lapisan tipis dari matrix silver alginate, lembut dan nyaman, serta dapat menyesuaikan dengan bentuk luka yang dalam hingga luka yang sulit dijangkau oleh dressing. Penggunaan Dressing Healoderm bertujuan untuk mengendalikan tingkat hidrasi jaringan dengan menciptakan tekanan osmotik tinggi, yang muncul pertama dan dipertahankan selama pembentukan kulit baru dan dalam fase inflamasi penyembuhan luka. luka kaki diabetic [6].

Artikel kedua: Konsumsi teh hijau yang teratur dapat mempertahankan kadar polifenol darah tetap tinggi. Penggunaan teh hijau secara teratur secara signifikan akan mengembangkan neoformasi sel epitel. Pemberian teh hijau pada tikus selama 2 minggu sebelum tindakan bedah dapat meningkatkan pembentukan jaringan epitel baru (neoformasi sel epitel), sehingga dapat mempercepat penyembuhan luka kaki diabetik[14] .

Pemberian teh hijau dapat dikombinasikan dengan senyawa aktif lain untuk meningkatkan kesembuhan luka. Teh hijau dikombinasikan dengan chitosan dapat meningkatkan penyembuhan luka dengan meningkatkan kekuatan luka insisi. Pada luka insisi, periode epitelisasi dipercepat. Pelepasan polifenol dari kompleks Chitosan dipertahankan stabil selama 6 jam setelah injuri [15]. Kekuatan luka semakin meningkat ketika luka mendekati kesembuhan khususnya luka kaki diabetik

Artikel ketiga: Perawatan luka modern harus tetap memperhatikan tiga tahap, yakni mencuci luka, membuang jaringan mati, dan memilih balutan. Mencuci luka bertujuan menurunkan jumlah bakteri dan membersihkan sisa balutan lama, debridement jaringan nekrotik atau membuang jaringan dan sel mati dari permukaan luka.

Intervensi perawatan luka konvensional harus sering mengganti kain kasa pembalut luka, sedangkan perawatan luka modern memiliki prinsip menjaga kelembapan luka dengan menggunakan bahan seperti hydrogel. Balutan dapat diaplikasikan selama tiga sampai lima hari, sehingga tidak sering menimbulkan trauma dan nyeri pada saat penggantian balutan dipilih bahan balutan yang menyerap cairan seperti foam, sedangkan pada luka yang sudah mulai tumbuh granulasi, diberi gel untuk membuat suasana lembap yang akan membantu mempercepat penyembuhan kaki diabetik [II] .

Artikel ke empat. Madu dianggap cocok dalam perawatan luka karena secara klinik terbukti memiliki zat anti mikroba, mampu mempertahankan moisture balance, mampu menstimulasi pertumbuhan jaringan, mampu menstimulasi aktifitas anti inflamasi dan mampu menstimulasi autolytik debridement. [16]

Keuntungan madu dari segi ekonomi dianggap murah karena dalam penggunaannya cukup dengan mengoleskan ke permukaan luka. Pada aplikasinya semua madu secara klinis dapat digunakan sebagai dressing pada luka [12].

Artikel ke Lima: Membersihkan permukaan luka pada prinsipnya agar dapat mengangkat bakteri dan drainase. Cairan pencuci luka, Normal saline sebagai cairan steril fisiologis diantaranya dapat dipakai untuk membersihkan luka tanpa membahayakan jaringan yang baru tumbuh [13].

\section{KESIMPULAN}


I. Modern wound dressing adalah pilihan yang tepat untuk meningkatkan proses penyembuhan luka kaki diabetes dengan efektifitas biaya perawatan yang lebih hemat .

2. Pemberian teh hijau secara topikal dapat meningkatkan kekuatan luka dan meningkatkan epitelisasi jaringan luka.Perlu penelitian teh hijau lebih lanjut untuk menentukan dosis optimal sehingga dapat diaplikasikan dalam meningkatkan kesembuhan luka kaki diabetes.

3. Prinsip utama dalam manajemen perawatan luka adalah pengkajian luka yang komprehensif agar dapat menentukan keputusan klinis yang sesuai dengan kebutuhan pasien. Diperlukan peningkatan pengetahuan dan keterampilan klinis untuk menunjang perawatan luka yang berkualitas, terutama dalam penggunaan modern dressing.

4. Madu saat ini telah menjadi trend dalam perawatan luka. Penelitian terkait madu dalam penyembuhan luka sudah banyak. Manfaat lain madu dalam perawatan luka adalah menurunkan jumlah eksudat. Penurunan jumlah eksudat ini mengakibatkan menurunnya malodor. Penggunaan madu dalam perawatan luka dapat meningkatkan tingkat kesembuhan lukan kaki diabetes dan memberikan kenyamanan bagi pasien.

5. Membersihkan permukaan luka pada prinsipnya agar dapat mengangkat bakteri dan drainase. Cairan pencuci luka, Normal saline sebagai cairan steril fisiologis

diantaranya dapat dipakai untuk membersihkan luka tanpa membahayakan jaringan yang baru tumbuh.

\section{UCAPAN TERIMA KASIH}

Penulis sadar banyak hambatan dalam proses penyusunan penelitian ini, dikarenakan keterbatasan kemampuan penulis sendiri. Oleh Karena itu penulis sampaikan banyak terimakasih kepada semua pihak yang telah memberikan bantuannya, utamanya kepada yang terhormat:

I. Ketua Yayasan Eka Harap

2. Ketua STIKes Eka Harap

3. Kaprodi Sarjana Ilmu Keperawatan STIKES Eka Harap

4. Kaprodi Profesi Ners STIKES Eka Harap

\section{REFERENSI}

I. American Diabetes Association. Diagnosis and Classification of Diabetes Mellitus. ADA. 2014.

2. Boedisantoso R., Soegondo S, Suyono S, Waspadji S, Gultom Y, Tambunan. Penatalaksanaan Diabetes Melitus Terpadu. Ist ed. Jakarta: FKUI; 2009.

3. International Diabetes Federation (IDF) (. IDF Diabetes Atlas 7th edition, [Internet]. IDF. 2015. Available from: doi: 10.1289/\%0Aimage.ehp.v| 19.i03.\%0D

4. Kemenkes RI. Riset Kesehatan Dasar 2018. Badan Penelitian dan Pengembangan Kesehatan, Kementerian Kesehatan Republik Indonesia. Jakarta: Kementerian Kesehatan RI; 2018.

5. PERKENI. Konsensus Pengelolaan dan Pencegahan Diabetes Mellitus Tipe 2 di Indonesia 20II. 4th ed. Jakarta: PERKENI; $201 \mathrm{I}$.

6. Handayani. Perawatan luka kaki diabetes dengan modern dressing. Jember,. UNmuh Jember. 2016;6(2):149-159.

7. Tiara, Shinta, Sukawana IW, dkk. Efektifitas Perawatan Luka Kaki Diabetik Menggunakan Balutan Modern Di Rsup Sanglah Denpasar Dan Klinik Dhalia Care. 2013;I(I):I-9. Available from: ojs.unud.ac.id/index.php/coping/article/downloa d/6453/4968

8. Bangu B, Yuhanah Y. Hubungan Pengetahuan dengan Kecemasan Ibu Pasca Imunisasi DPT Anaknya di Kelurahan Kolakaasi. J Surya Med. 2020;5(2):65-74.

9. Mutiudin Al, Program D, Keperawatan S, Bhakti U, Tasikmalaya K, Implant B, et al. Efektivitas proses penyembuhan luka dengan penggunaan modern wound dressing pada pasien ulkus diabetik: a sistematik review. 
2019;3(November).

10. Saryono. Potensi Teh Hijau Dalam

Penyembuhan Luka: Sistematik Review. Pros

Konf Nas PPNI jawa Teng 2013. 2013;202-5.

II. Kartika RW, Bedah B, Paru J, Luka AP.

Perawatan Luka Kronis dengan Modern

Dressing. Perawatan Luka Kronis Dengan Mod

Dress. 20I5;42(7):546-50.

12. RITONGA SH. MADU SEBAGAI AGEN DEBRIDEMENT:SYSTEMATIC REVIEW. J Kesehat IIm Indones. 2016; I I (2): I-I3.

13. Rika F, Elvi O. Aplikasi Modern Wound Care Pada Perawatan Luka Infeksi di RS Pemerintah Kota Padang. Nurse J Keperawatan. 2016;12(2): I59-65.

14. SY A, P P, M K, S E, Zamiri A MF, M., et al. Effect of green tea (Camellia sinensis) extract on healing process of surgical wounds in rat. Int J Surg. 201 3; I I (4):332-9.

15. Y Q, Wang HW KT, W K. Chitosan green tea polyphenol complex as a released control compound for wound healing. Chin J Traumatol; 2010;13(2):91-6.

16. $\mathrm{R} W$. The benefits of honey in wound management. Nurs Stand. 2005;20(I0):57-64. 